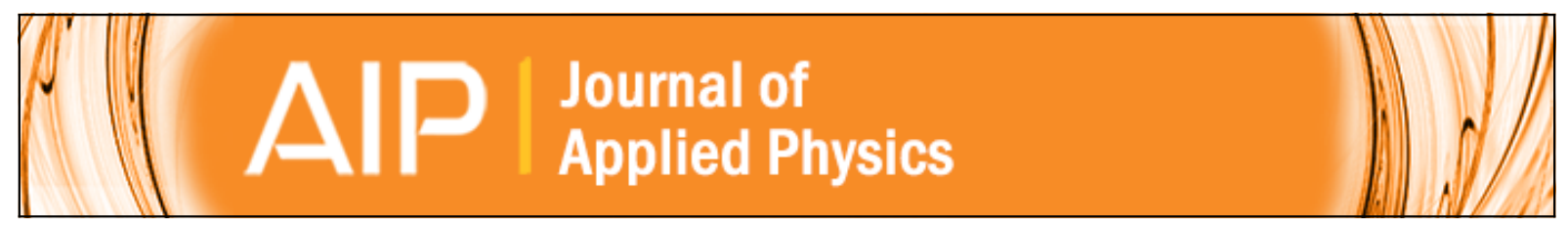

\title{
Study of mechanical alloying of Sm and Fe
}

D. Seifu, F. W. Oliver, E. Hoffman, A. Aning, V. Suresh Babu, M. S. Seehra, and R. M. Catchings

Citation: Journal of Applied Physics 81, 5805 (1997); doi: 10.1063/1.364674

View online: http://dx.doi.org/10.1063/1.364674

View Table of Contents: http://scitation.aip.org/content/aip/journal/jap/81/8?ver=pdfcov

Published by the AIP Publishing

\section{Articles you may be interested in}

Nanostructured icosahedral phase formation in Al $70 \mathrm{Cu} 20 \mathrm{Fe} 10$ by mechanical alloying: Comprehensive study J. Appl. Phys. 91, 5353 (2002); 10.1063/1.1464206

Sm-Fe-C nanocomposite magnets prepared from powders of Sm, Fe, and graphite by mechanical alloying J. Appl. Phys. 87, 5296 (2000); 10.1063/1.373326

Early stages of mechanical crystallization of amorphous FeZrBCu soft magnetic material J. Appl. Phys. 87, 2464 (2000); 10.1063/1.372203

Characterization of hard magnetic two-phase mechanically alloyed Sm 2 Fe $17 \mathrm{~N} 3$ /a-Fe nanocomposites J. Appl. Phys. 81, 6310 (1997); 10.1063/1.364389

Mössbauer analysis of the phase distribution of Fe 64.5 Co 18 B 16 SiC 0.5 soft magnetic samples in powder form

J. Appl. Phys. 81, 4655 (1997); 10.1063/1.365515

MIT LINCOLN LABORATORY CAREERS

Discover the satisfaction of innovation and service to the nation
- Space Control

- Air \& Missile Defense

- Communications Systems \& Cyber Security

- Intelligence, Surveillance and

Reconnaissance Systems

- Advanced
Electronics
- Tactical Systems
- Homeland
Protection
- Air Traffic Control

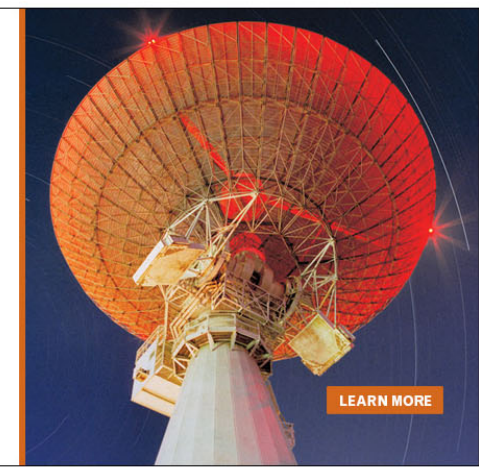




\title{
Study of mechanical alloying of Sm and Fe
}

\author{
D. Seifu, F. W. Oliver, and E. Hoffman \\ Department of Physics, Morgan State University, Baltimore, Maryland 21239
}

A. Aning

Department of Materials Science and Engineering, Virginia Polytechnic Institute and State University, Blacksburg, Virginia 24061

V. Suresh Babu and M. S. Seehra

Department of Physics, West Virginia University, Morgantown, West Virginia 26506-6315

R. M. Catchings

Department of Physics, Howard University, Washington, DC 20059

Mechanical alloying of $\mathrm{Sm}$ and $\mathrm{Fe}$ with the composition of $\mathrm{SmFe}_{3}$ was studied using x-ray-diffraction (XRD), Mössbauer, and magnetization measurements. Data taken as a function of milling time for up to $20 \mathrm{~h}$ show significant changes occurring during ball milling. The XRD studies show that the initial crystalline Bragg reflections changed to a broad maximum, which is attributed to the formation of an amorphous phase. The initial six-line pattern in the Mössbauer spectrum, characteristic of magnetic ordering, changed to a broad singlet, characteristic of a nonmagnetic material. Magnetization measurements revealed that the coercive field was at its maximum after 5 $\mathrm{h}$ of milling and decreased sharply as the milling time increased. The remanent magnetization was at its maximum between 5 and $10 \mathrm{~h}$ of milling. The final product of the ball milling, which exhibited the characteristics of an amorphous paramagnetic material in its XRD and Mössbauer spectrum, was studied after heat treatment. The XRD and the Mössbauer spectra of the heat treated alloy show that substantial changes occurred during heat treatment in that sharp Bragg reflections, characteristic of crystalline materials, reappear and the alloy changed from a paramagnetic to a ferromagnetic state.

(C) 1997 American Institute of Physics. [S0021-8979(97)32008-8]

\section{INTRODUCTION}

Mechanical alloying has been used during the last few years to prepare a variety of application related magnetic materials. ${ }^{1-5}$ This technique also allows one to prepare amorphous materials in compositional ranges that cannot be prepared by conventional means. ${ }^{6}$ Interest in studying the $\mathrm{Sm}-\mathrm{Fe}$ system is related to its role as a precursor of $\mathrm{Sm}-\mathrm{Fe}$ based magnetic materials, which constitute a very promising alternative to traditional permanent magnetic materials.

A review of the intrinsic magnetic properties of $\mathrm{REFe}_{3}$ (where RE denotes rare earth) is given by Buschow. ${ }^{7}$ The Curie temperature of $\mathrm{SmFe}_{3}$ is about $380{ }^{\circ} \mathrm{C}$ with a saturation magnetization of $4.5 \mu_{B}$. The easy magnetization direction is along the $c$ axis over the whole ferromagnetic temperature range, as determined by Mössbauer spectroscopy. ${ }^{8}$ The $\mathrm{SmFe}_{3}$ phase crystallizes in the hexagonal $\mathrm{PuNi}_{3}$ structure (space group $R \overline{3} \mathrm{~m}$ ) which consists of an alternate stacking of three $\mathrm{RETM}_{5}\left(\mathrm{CaCu}_{5}\right.$ type) and three $\mathrm{RE}_{2} \mathrm{TM}_{4}$ (Lavesphase type) layers ${ }^{9}$ (where TM denotes transition metal).

The goal of this work is to prepare, characterize and measure the magnetic properties of mechanically synthesized $\mathrm{SmFe}_{3}$. X-ray diffraction (XRD) was used to measure longrange atomic ordering, while Mössbauer measurement was used to sense the immediate environment of the absorbing nucleus. The $14.4 \mathrm{keV}$ gamma ray in ${ }^{57} \mathrm{Fe}$ was used as a probe to follow the mechanical alloying process. The XRD and the Mössbauer spectra indicate that the mechanically alloyed $\mathrm{SmFe}_{3}$ became amorphous and paramagnetic after $20 \mathrm{~h}$ of milling. Heat treatment at $650{ }^{\circ} \mathrm{C}$ for $1 \mathrm{~h}$ changed it back to a crystalline, ferromagnetic $\alpha$-Fe phase and an unidentified crystalline phase.

\section{EXPERIMENT}

The starting materials used for mechanical alloying were elemental powders of $\alpha$-Fe having a purity of $99.9 \%$ and particle size $300 \mu \mathrm{m}$, and Sm having a purity of $99.9 \%$ and particle size $44 \mu \mathrm{m}$. The elemental powder of $\alpha$-Fe and Sm was mixed in the proportions $\mathrm{SmFe}_{3}$. High-energy ball milling was carried out for up to $20 \mathrm{~h}$ in an argon atmosphere using a SPEX $8000 \mathrm{mixer} / \mathrm{mill}$ and stainless-steel balls and a container with a ball-to-powder ratio of 4 to 1 . A small amount of reaction product was removed from the vial for analysis at various intermediate stages in the milling process. A sample of the $20 \mathrm{~h}$ milled product was annealed at $650{ }^{\circ} \mathrm{C}$ for $1 \mathrm{~h}$ in an Ar atmosphere and was cooled to room temperature in an Ar atmosphere for analysis.

$\mathrm{X}$-ray analysis of the samples was made on an x-ray powder diffractometer with $2 \theta$ geometry using $\mathrm{Cu} K \alpha$ radiation. Mössbauer measurements were performed in standard transmission geometry and at constant acceleration using a $25 \mathrm{mCi}{ }^{57} \mathrm{Fe}$ source in a $\mathrm{Rh}$ matrix. The absorber, a pellet 2 $\mathrm{mm}$ thick and $20 \mathrm{~mm}$ in diameter, was a mixture of the powder sample and anhydrous dextrose mixed at room temperature. Evaluation of the sampled data was done using a least-squares-fit program assuming Lorentzian line shape with a parabolic baseline. Magnetic measurements were performed with a superconducting quantum interference device (SQUID) magnetometer (Quantum Design model MPMS). All measurements were carried out at room temperature.

\section{RESULTS AND DISCUSSION}

\section{A. Sample characterization}

The XRD patterns obtained after $1,3,5$, and $10 \mathrm{~h}$ of milling are shown in Fig. 1. The line intensity of $\alpha$-Fe at 


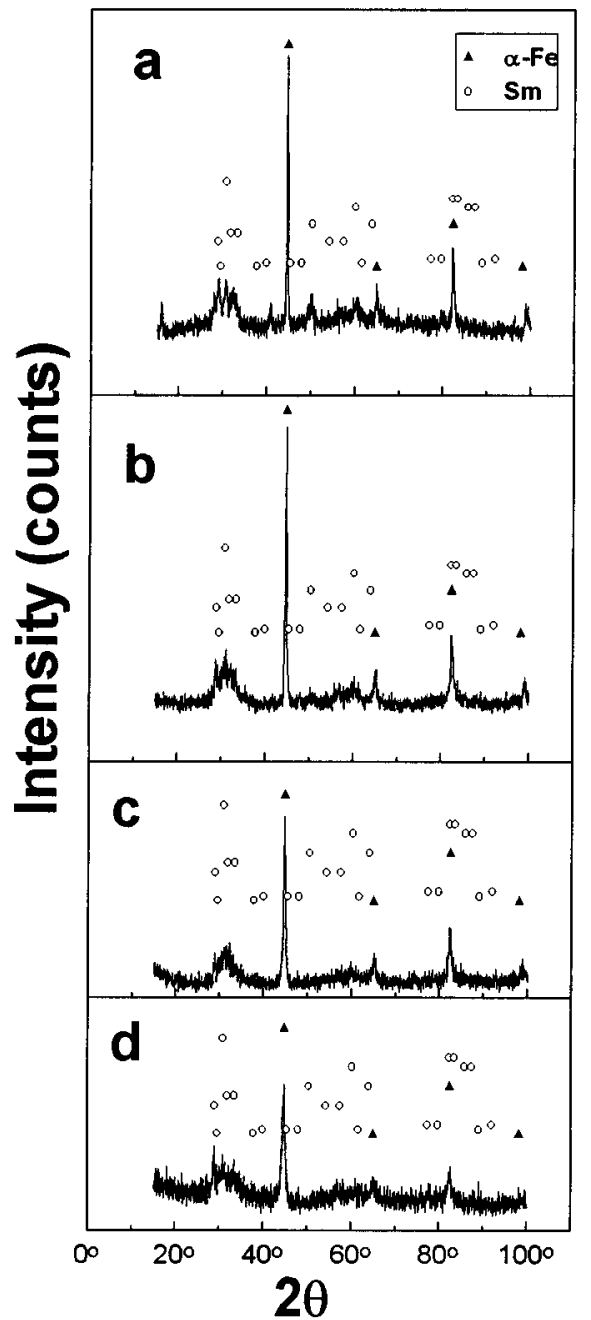

FIG. 1. X-ray-diffraction patterns of mechanically alloyed $\mathrm{Sm}$ and Fe (a) milled for $1 \mathrm{~h}$, (b) milled for $3 \mathrm{~h}$, (c) milled for $5 \mathrm{~h}$, and (d) milled for $10 \mathrm{~h}$.

$44.7^{\circ}$ decreased with milling time indicating a reduction in the amount of pure $\alpha$-Fe present. A small increase in the line broadening with milling time is also observed, which is due to smaller particle size. Figure 2(a) shows the XRD pattern of the $20 \mathrm{~h}$ mechanically alloyed $\mathrm{SmFe}_{3}$. The diffractogram of the $20 \mathrm{~h}$ milled sample shows a broad line indicating the absence of a crystalline phase. Figure 2(b) shows the XRD of the $20 \mathrm{~h}$ milled sample after heat treatment at $650^{\circ} \mathrm{C}$ for $1 \mathrm{~h}$;

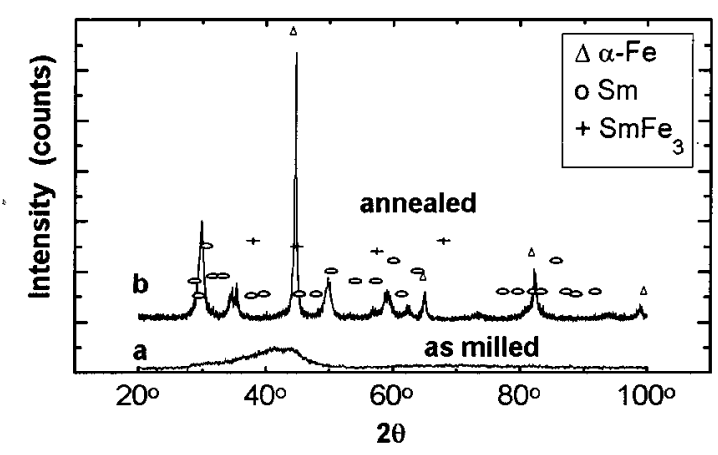

FIG. 2. X-ray-diffraction patterns of mechanically alloyed $\mathrm{Sm}$ and Fe milled for $20 \mathrm{~h}$ (a) as milled, (b) annealed for $1 \mathrm{~h}$ at $650^{\circ} \mathrm{C}$.

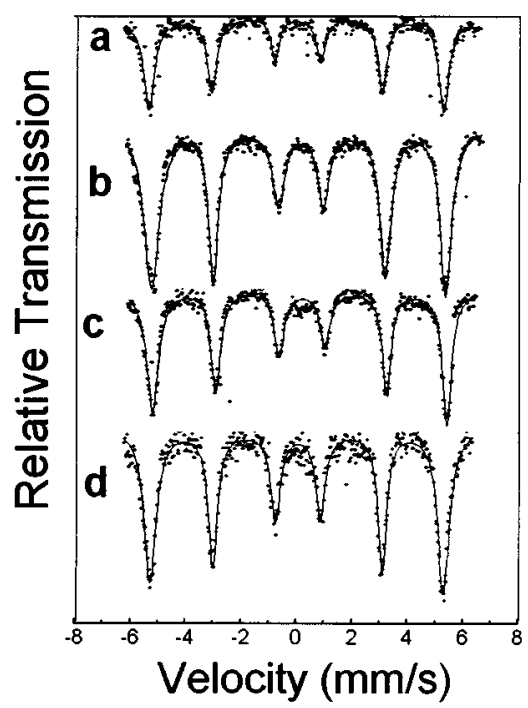

FIG. 3. Mössbauer spectra of mechanicaly alloyed $\mathrm{Sm}$ and $\mathrm{Fe}$ (a) milled for $1 \mathrm{~h}$, (b) milled for $3 \mathrm{~h}$, (c) milled for $5 \mathrm{~h}$, and (d) milled for $10 \mathrm{~h}$. The solid lines are Lorentzian fits.

sharp diffraction lines are observed, corresponding to wellcrystallized alloys. From the XRD spectra it can be concluded that the material formed by mechanical milling is an amorphous alloy which crystallizes during annealing at $650{ }^{\circ} \mathrm{C}$. Since amorphous alloys are stable only below the glass transition temperature $T_{g}$, a requirement for the formation of amorphous alloy by mechanical milling is that the milling take place below $T_{g}$. For pure iron, $T_{g}$ is far below room temperature; therefore, one or more other elements must be present in order to stabilize the amorphous structure at room temperature. As shown by Shaaf et al. ${ }^{10}$ prolonged milling transforms pure $\alpha$-Fe to nanocrystalline state, but never to an amorphous phase. In this work the Sm atoms served as a stabilizing element in the formation of the amorphous phase. The stability of the amorphous phase is also influenced by the concentration of the elements in the alloy. It has been shown by Murillo et al. ${ }^{11}$ that for $\mathrm{Sm}_{30} \mathrm{Fe}_{70}$ milled for up to $60 \mathrm{~h}$ there is still a pure $\alpha$-Fe peak in the x-ray diffraction; but, as shown in this work, for $\mathrm{SmFe}_{3}$ milled for up to $20 \mathrm{~h}$, no crystalline $\alpha$-Fe phase is observed in the XRD.

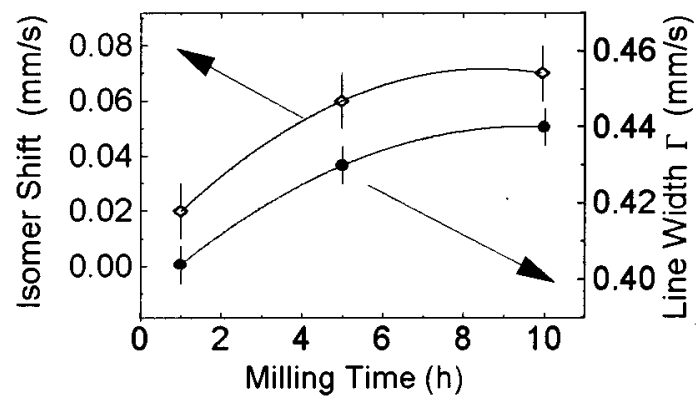

FIG. 4. Isomer shift and linewidth of mechanically alloyed Sm and Fe as a function of milling time. 


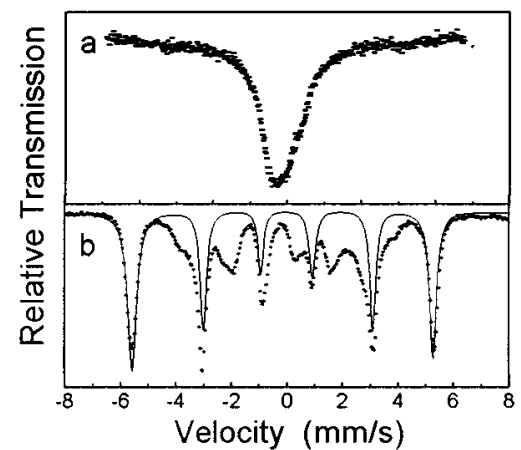

FIG. 5. Mössbauer spectra of mechanically alloyed Sm and Fe (a) milled for $20 \mathrm{~h}$, and (b) milled for $20 \mathrm{~h}$ and annealed at $650{ }^{\circ} \mathrm{C}$ for $1 \mathrm{~h}$. The solid lines correspond to the subspectrum of the $\alpha$-Fe phase.

\section{B. Mössbauer measurements}

Mössbauer spectra of milled Sm and Fe at different milling times are shown in Fig. 3. Between 1 and $10 \mathrm{~h}$ of milling no significant change was observed in the spectra. As shown in Fig. 4, however, the isomer shift and the linewidth increased with milling time. The increase in linewidth is well correlated with the decrease in particle size, and the increase in the isomer shift is due to a simultaneous increase in both microstrain and lattice constant. Since the ${ }^{57} \mathrm{Fe}$ Mössbauer isomer shift can be taken as a measure of the $s$-electron charge density at the Fe nucleus, its increase also indicates reduction in the electron density.

The Mössbauer spectrum of Sm and Fe milled for $20 \mathrm{~h}$ is shown in Fig. 5(a). Although as for most Fe-rich amorphous compounds the two peaks are poorly resolved, the spectrum can be well described by fitting the data to two independent Lorentzians. The two peak positions then define the effective isomer shift and the effective quadrupole splitting. The isomer shift with respect to that of $\alpha$-Fe is $-0.18 \pm .01 \mathrm{~mm} / \mathrm{s}$. The isomer shift is negative, as is typical of most amorphous $\mathrm{RE}-\mathrm{Fe}$ and amorphous TM-Fe compounds. The small asymmetry observed in the spectra of amorphous $\mathrm{SmFe}_{3}$ is empirically explained to be a correlation between the isomer shift and the electric-field gradient. The quadrupole splitting is $0.48 \pm .01 \mathrm{~mm} / \mathrm{s}$.

Figure 5(b) shows the Mössbauer spectrum of $\mathrm{Sm}$ and Fe milled for $20 \mathrm{~h}$ and then annealed for $1 \mathrm{~h}$ at $650{ }^{\circ} \mathrm{C}$ in an argon atmosphere. The spectrum shows lines consistent with crystalline $\alpha$-Fe (solid lines) plus other weaker lines.

\section{Magnetic properties}

Figure 6 shows the coercive field and the remanent magnetization, determined from measured hysteresis loops, of mechanically alloyed $\mathrm{Sm}$ and $\mathrm{Fe}$ as a function of milling time. The coercive field increased from $44 \mathrm{G}$ after $1 \mathrm{~h}$ of milling to $569 \mathrm{G}$ after $5 \mathrm{~h}$ and then decreased to $16 \mathrm{G}$ after $20 \mathrm{~h}$ of milling. This sharp decrease in the coercive field after $5 \mathrm{~h}$ of milling is due to the reduction of particle size, and other factors such as increase of mechanical stresses, formation of new grain boundaries, and amorphization of the material. The remanent magnetization showed a peak that was similar, but displaced to a milling time an hour or two

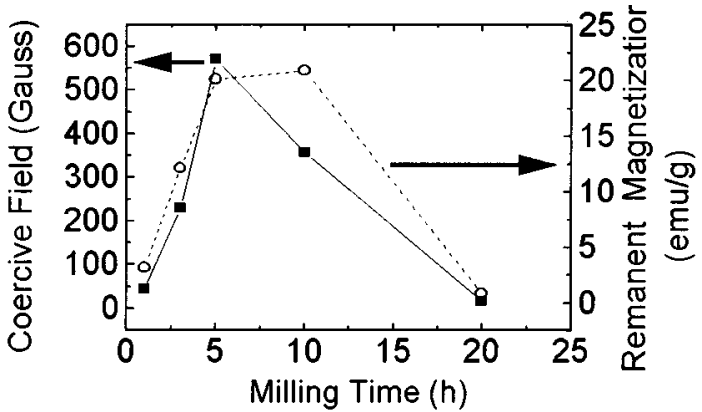

FIG. 6. Coercive field and remnant magnetization of mechanically alloyed $\mathrm{Sm}$ and $\mathrm{Fe}$ as a function of milling time. The lines are drawn connecting the points as a guide.

longer. It began at $3.21 \mathrm{emu} / \mathrm{g}$, increased to $20.9 \mathrm{emu} / \mathrm{g}$ at 10 $\mathrm{h}$, and dropped to $0.89 \mathrm{emu} / \mathrm{g}$ at $20 \mathrm{~h}$ of milling.

The coercive field and the remanent magnetization of the $20 \mathrm{~h}$ milled alloy increased after heat treatment. The coercive field increased to $25.0 \mathrm{G}$ and the remanent magnetization increased to $2.52 \mathrm{emu} / \mathrm{g}$.

The saturation magnetization, also determined from measured hysteresis loops, decreased with milling time. After $1 \mathrm{~h}$ of milling the saturation magnetization was $80 \mathrm{emu} / \mathrm{g}$, and $20 \mathrm{~h}$ of milling reduced it to $32 \mathrm{emu} / \mathrm{g}$. Heat treatment increased the saturation magnetization of the $20 \mathrm{~h}$ milled sample to $88 \mathrm{emu} / \mathrm{g}$.

\section{CONCLUSIONS}

This study has revealed that $\mathrm{Sm}$ and Fe mechanically milled for up to $20 \mathrm{~h}$ became an amorphous alloy which crystallized when annealed. The coercive field and the remanent magnetization of mechanically alloyed sample were at their maximum after about $5 \mathrm{~h}$ of milling. The saturation magnetization after $20 \mathrm{~h}$ of milling decreased to less than half of its value after $1 \mathrm{~h}$ of milling. Heat treatment increased the saturation magnetization of the $20 \mathrm{~h}$ milled alloy above that of the $1 \mathrm{~h}$ milled alloy.

As shown in this study, formation of the $\mathrm{SmFe}_{3}$ phase occurred between 10 and $20 \mathrm{~h}$ of the mechanical synthesis. Therefore, it is important to sample the product at short intervals during this process in order to observe the alloy in transition from a ferromagnetic crystalline state to a paramagnetic amorphous state.

${ }^{1}$ J. S. Benjamin, Sci. Am. 234, 40 (1976).

${ }^{2}$ L. Schultz, J. Wecker, and E. Hellstern, J. Appl. Phys. 61, 3583 (1987).

${ }^{3}$ L. Schultz, K. Schnitzke, J. Wecker, M. Katter, and C. Kuhrt, J. Appl. Phys. 70, 6339 (1991)

${ }^{4}$ J. Wecker, M. Katter, K. Schnitzke, and L. Schultz, J. Appl. Phys. 69, 5847 (1991).

${ }^{5}$ P. A. I. Smith, J. Ding, R. Street, and P. G. McCormick, Scr. Mater. 34, 61 (1996).

${ }^{6}$ K. H. J. Buschow, Philips Tech. Rev. 42, 48 (1985).

${ }^{7}$ K. H. J. Buschow, Rep. Prog. Phys. 40, 1179 (1977).

${ }^{8}$ A. M. Van der Kraan, J. N. J. Van der Velden, J. H. F. Van Apeldoorn, P. C. M. Gubbens, and K. H. J. Buschow, Phys. Status Solidi A 35, 137 (1976).

${ }^{9}$ K. Itoh, T. Okagaki, and K. Kanematsu, J. Phys. Soc. Jpn. 58, 1787 (1989).

${ }^{10}$ P. Schaaf, G. Rixecker, E. Yang, C. N. J. Wagner, and U. Gonser, Hyperfine Interact. 94, 2239 (1994).

${ }^{11}$ N. Murillo, J. Gonzalez, F. Cebollada, V. E. Martin, J. M. Gonzalez, and L. Schultz, IEEE Trans. Magn. MAG-29, 2857 (1993). 